\title{
Implementation of multi-criteria decision making approach for the team leader selection in IT sector
}

\author{
Sandhya $^{a^{*}}$, R. K. Garg ${ }^{\mathrm{b}}$ and Rakesh Garg
}

${ }^{a}$ Department of Applied Science \& Engineering, Gateway Institute of Engineering \& Technology, Sonipat, Haryana, India

${ }^{b}$ Department of Mechanical Engineering, Deenbandhu Chhotu Ram University of Science \& Technology, Sonipat, Haryana, India ${ }^{c}$ Department of Computer Science \& Engineering, Hindu College of Engineering, Sonipat, Haryana, India

\section{H R O N I C L E}

Article history:

Received: October 1, 2016

Received in revised format: No-

vember 16, 2016

Accepted: March 3, 2017

Available online:

March 6, 2017

Keywords:

Team Leader

Multi-criteria decision making

$E D B A$

\section{A B S T R A C T}

In the era of technology, the demand of the software development increases at a very high speed, as software has touched the human's life in all aspects. The better quality software development acquiring minimum development time leads to the team work in which a group of people has been formed that work together in a team for the software development. One of the most significant issues in effective and efficient teamwork is the team leader selection because the team leader is the person in any team that is going to handle all types of managerial activities such as leadership, motivation to others, etc. The team leader selection process may be dependent on numerous conflicting selection indexes that make it a Multi-Criteria Decision Making (MCDM) problem. In the present research, an MCDM approach namely, Euclidean Distance Based Approximation (EDBA) which is based on the calculation of the composite distance value for each alternative from a hypothetical optimal point is presented. The result of this study provides a comprehensive ranking of team leaders that leads to the right selection of team leader in information technology (IT) sector.

\section{Introduction}

The concept of team work is highly suggested now a day for the software development that minimizes the development time and leads to the better quality software development (Omar et al., 2011; Figl, 2010; Yu et al., 2009; Humphrey, 2006; Marques \& Ochoa, 2014). Therefore, selecting the team members and specially team leader seems to be very crucial for timely completion of the project (Gilley at al., 2010; Rong \& Shao, 2012). Tseng et al. (2009) argued about the capabilities of a team leader for deciding the work flow to minimize the time of design and effectively use of all team members for the achievement of the main goal. The prime role of a team leader in the project development is to provide the directions in some specific way to other team members for the organization of work so that all team members could contribute to complete the work timely (Zaccaro et al., 2002). In the contemporary work, Rutherfoord (2006) emphasized on the personality of team leader that manage disagreements,

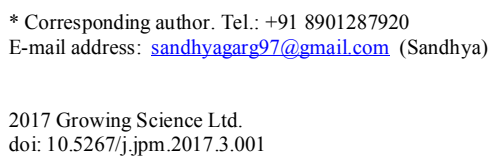


call meetings and interface with higher and lower authorities of the organization. Palmer and Summers (2011) discussed the importance of leadership in undergraduate engineering projects and suggested that the wrong team formation can affect various attributes like confidence of other team members, communication between the team members and the project outcome also. Deniz and Metin (2009) suggested that the problem of team leader selection may involve a number of selection criteria. So, this problem can be considered as a multi-criteria decision making problem (MCDM). A lot of selection criteria such as personality, academic achievement, teamwork experience, programming skills and MCDM approaches like analytical hierarchy process (AHP) were proposed by the various researchers to solve the problem of team leader selection (Acuna et al., 2009; Capretz \& Ahmed, 2010; Omar \& Abdullah, 2010; Omar et al., 2010; Antoniadis, 2012; Alkadi \& Beaubouef, 2008; Amit et al., 2014). The right selection of team leader is very essential because incorrect selection of team leader can result in the project failure (Marques \& Ochoa, 2014; Rovira et al., 2012). The present study is based on the concept of the representation of team leader selection problem as an MCDM problem and a novel MCDM approach namely Euclidean Distance Based Approximation (EDBA) is proposed to solve the same. The rest of the paper is organized as follows. Section 2 describes the research methodology adopted concerning to the formation of evaluation process, description of the selection indexes and proposed approach whereas an empirical study is provided in section 3 to show the applicability. Section 4 covers the results and conclusion of the present research is provided in section 5 of the paper.

\section{Research methodology}

The present research emphasizes on the development of an MCDM approach for the team leader selection for any organization. The empirical study chooses 4-team leaders, 4-selection indexes and 1MCDM approach. This section presents the description of the proposed evaluation approach, selection indexes and MCDM approach.

\subsection{MCDM approach for team leader selection}

Assessing the quality of a team leader is one of the fundamental questions that must be addressed in team leader selection process. Although it is extremely difficult because of lack of objective measures to evaluate, it is of great importance for successful timely completion of any software project. This research paper develops comprehensive evaluation procedure as provided in Fig. 1.

\section{Team leaders}

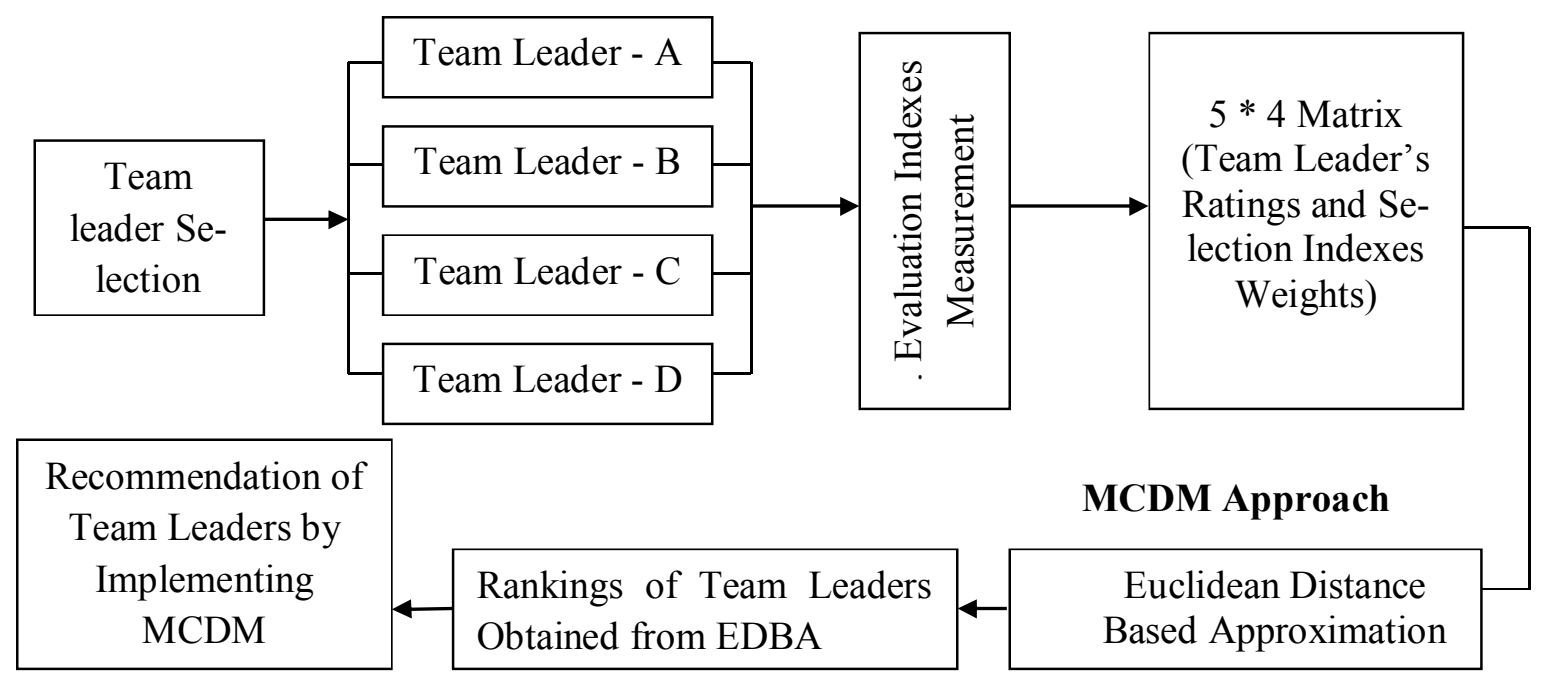

Fig 1. Team Leader Selection Process Framework 


\subsection{Selection Indexes}

The main emphasis of the present research is to model the team leader selection problem as an MCDM problem. So, to get a comprehensive evaluation, the empirical study presented in this work considers 4 evaluation indexes namely; Personality, Academic achievement, Teamwork experience and Programming skills. TheA brief description along with their priority weights of these selection indexes is provided in Table 1.

\section{Table 1}

Selection Indexes Description

\begin{tabular}{cllc}
\hline S. No. & \multicolumn{1}{c}{ Selection Index } & \multicolumn{1}{c}{ Description } & Priority Weights \\
\hline 1 & Personality & Qualities exhibited by an individual showing his/her uniqueness. & 0.54 \\
2 & Academic achievement & Individual's educational success. & 0.13 \\
3 & Teamwork experience & Capability to work efficiently and effectively in a group. & 0.27 \\
4 & Programming skills & Ability to write codes for any software project. & 0.06 \\
\hline
\end{tabular}

\subsection{MCDM approach}

A variety of MCDM approaches have been developed by the various researchers in the past and widely accepted to solve many problems such as inventory policies selection (Gupta et al., 2013, 2014), Elearning website selection (Jain et al., 2015, 2016), power plant evaluation and selection (Gupta \& Garg, 2014), software engineering metrics selection (Garg et al., 2013), vendor selection (Jarial \& Garg, 2012), COTS selection (Garg et al., 2016, 2017) etc. In this research, an MCDM analytical approach has been selected for the performance evaluation of the team leaders to make the right selection. The working principal of the EDBA focuses on specifying objective's optimal state represented by optimal model i.e. OPTIM and the ideal values for all the selection indexes considered. The vector $\mathrm{O},\left(\mathrm{a}_{1} . \mathrm{a}_{2}\right.$, $\left.\ldots . a_{n}\right)$ is a set of finest values for all evaluation indexes that acts as the optimal point in a n-dimensional space. Here, the best values for all indexes are considered as the finest values. So, OPTIM, refers simply to the team leader possessing the best values for all indexes considered. The chances of the occurrence of any certain alternative as OPTIM are very less that result in the consideration of various alternatives to simulate the OPTIM. In this case, OPTIMA acts as a reference point to which all the alternatives are compared quantitatively. The difference arising from this quantitative comparison shows the alternate's team leader's fitness to attain the OPTIM. Therefore, here, the judgment problem is to find a feasible solution closest to the OPTIM and the objective function to find a particular solution can be designed as:

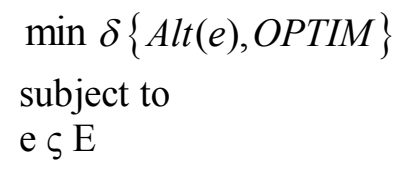

where $\{\operatorname{Alt}(e)\}$, and $\delta$ show an alternate team leader in the n-dimensional space, and the distance from OPTIM, respectively.

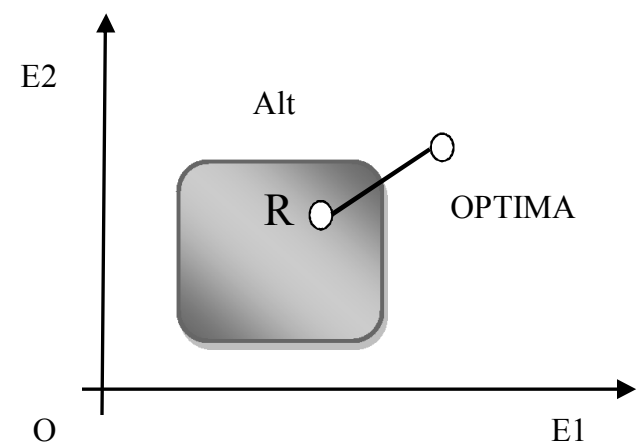

Fig 2. Solution Function in 2 - Dimensional Space 
It can be stated further that both the problem and its solution here are dependent on two objects OPTIM and $\delta$. The representation of this solution function in 2-dimensional space is given in Fig. 2, where $H$ is the feasible region and the OP is the optimal point.

The EDBA finds the point in the feasible region ' $\mathrm{R}$ ' closest to the OPTIM, and is shown in Fig. 3. Note that the lines $(A l t-O P T)_{E 1}$, and $(A l t-O P T)_{E 2}$ are parallel to the E1, and E2 axis, respectively. Therefore $(A l t-O P T)_{E 1}=\left|O P T_{E 1}-A l t_{E 1}\right|$ and $(A l t-O P T)_{E 2}=\left|O P T_{E 2}-A l t_{E 2}\right|$. In 2-dimensional space, $\delta$ is given by

$$
\delta=\left[\left(O P T_{E 1}-A l t_{E 1}\right)^{2}+\left(O P T_{E 2}-A l t_{E 2}\right)^{2}\right]^{1 / 2}
$$

In general terms, the "distance $\delta$ " can be formulated as

$$
\delta=\left[\sum\left(O P T_{i j}-A l t_{i j}\right)^{2}\right]^{1 / 2}
$$

where $i=1,2, \ldots, \quad n=$ alternate team leader and $j=1,2, . ., \quad m=$ Selection indexes

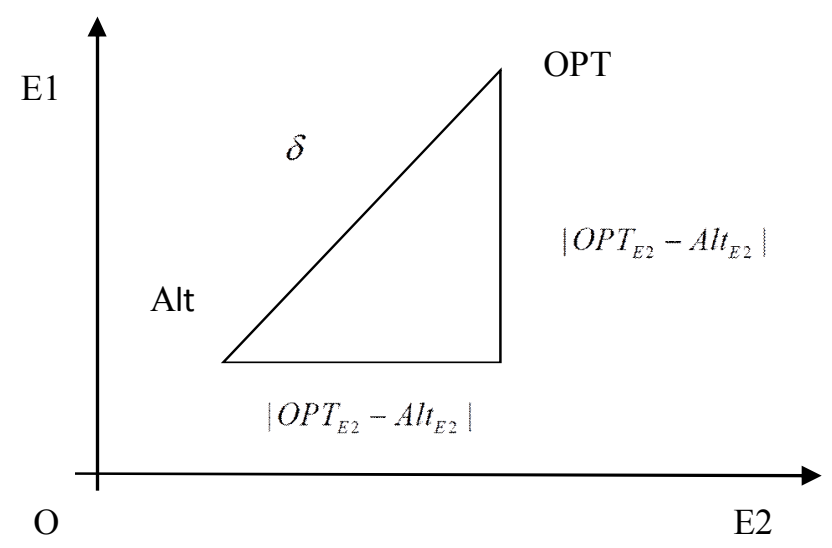

Fig 3. Distances of Real Vector in 2 - Dimensional Space

To employ EDBA, let us consider ' $\mathrm{n}$ ' team leaders and ' $\mathrm{m}$ ' selection indexes related to each alternate e.g. $\operatorname{Alt}_{1}\left(a_{11}, a_{12}, \ldots, a_{1 m}\right), \operatorname{Alt}_{2}\left(a_{21}, a_{22}, \ldots, a_{2 m}\right), \operatorname{Alt}_{n}\left(a_{n 1}, a_{n 2}, \ldots, a_{n m}\right)$, and the OPTIM $\left(a_{b 1}, a_{b 2}, \ldots, a_{b m}\right)$ where $a_{b m}=$ the finest value of the selection index ' $\mathrm{m}$ '.

Thus, the whole set of team leaders can be given using the adjusted values of the selection index by the matrix:

$$
[a]=\left[\begin{array}{cccc}
a_{11} & a_{12} & \ldots & a_{1 m} \\
a_{21} & a_{22} & \ldots & a_{2 m} \\
\vdots & \vdots & \vdots & \vdots \\
a_{n 1} & a_{n 2} & \ldots & a_{n m} \\
a_{b 1} & a_{b 2} & \ldots & a_{b m}
\end{array}\right]
$$

Now, the matrix is standardized to eliminate the influence of different measurement units using

$$
Z_{i j}=\frac{a_{i j}-\overline{a_{j}}}{S_{j}}
$$


Here

$$
\bar{a}_{j}=\frac{1}{n} \sum_{i=1}^{n} a_{i j}
$$

and

$$
S_{j}=\left[\frac{1}{n} \sum_{i=1}^{n}\left(a_{i j}-\bar{a}_{j}\right)^{2}\right]^{1 / 2},
$$

where $i=1,2,3, \ldots, n$, and $\mathrm{j}=1,2,3, \ldots, m$.

$\bar{a}_{j}$, and $s_{j}$ show the average value, and the standard deviation of each index for all alternate team leader. The standardized matrix is formulated as:

$$
\left[Z_{S}\right]=\left[\begin{array}{cccc}
Z_{11} & Z_{12} & \ldots & Z_{1 m} \\
Z_{21} & Z_{22} & \ldots & Z_{2 m} \\
\vdots & \vdots & \vdots & \vdots \\
Z_{n 1} & Z_{n 2} & \ldots & Z_{n m} \\
Z_{O P T 1} & Z_{O P T 2} & \ldots & Z_{O P T m}
\end{array}\right]
$$

where $Z_{11}=\frac{a_{11}-\bar{a}_{1}}{S_{1}}, Z_{12}=\frac{a_{12}-\bar{a}_{2}}{S_{2}}, Z_{1 m}=\frac{a_{1 m}-\bar{a}_{m}}{S_{m}}$.

The next step is to calculate the alternative's differences to the OPTIM, by subtracting elements of the optimal set by a corresponding element in the alternatives set that result in a new matrix known as distance matrix and is given as:

$$
\left[Z_{d}\right]=\left[\begin{array}{cccc}
z_{\mathrm{OPT} 1}-Z_{11} & Z_{O P T 2}-Z_{12} & \ldots & Z_{O P T m}-Z_{1 m} \\
Z_{\mathrm{OPT1} 1}-Z_{21} & Z_{O P T 2}-Z_{22} & \ldots & Z_{O P T m}-Z_{2 m} \\
\ldots & \ldots & \ldots & \ldots \\
Z_{\mathrm{OPT} 1}-Z_{n 1} & Z_{O P T 2}-Z_{n 2} & \ldots & Z_{O P T m}-Z_{n m}
\end{array}\right]
$$

Finally, the Euclidean distance, ED, between each feature selection algorithm to the OPTIM, is calculated using

$$
E D_{O P T-A l t}=\left[\sum_{j=1}^{m}\left(Z_{O P T j}-Z_{i j}\right)^{2}\right]^{1 / 2} \text {. }
$$

Simply, this Euclidean distance can be taken as the mathematical expression of various distances on each selection index for which the team leaders are evaluated and finally ranked.

\section{Empirical Study}

The empirical study is carried out to validate the proposed MCDM approach for the performance evaluation and selection of team leaders for the development of any software project. A data set including four team leaders by considering four selection indexes as provided in (Muhisn et al., 2015) was selected in this research. All the four selection indexes have their own significance in the evaluation and selection process. The performance ratings of 4-leaders against the 4-selection indexes are provided in Table 2 given below.

\section{Table 1}

Performance Ratings of Team leaders

\begin{tabular}{ccccc}
\hline $\begin{array}{c}\text { Team } \\
\text { Leader }\end{array}$ & Personality & Academic achievement & Teamwork Experience & $\begin{array}{c}\text { Programming } \\
\text { skills }\end{array}$ \\
\hline A & 0.46 & 0.44 & 0.47 & 0.41 \\
B & 0.27 & 0.29 & 0.28 & 0.29 \\
C & 0.10 & 0.15 & 0.16 & 0.19 \\
D & 0.17 & 0.12 & 0.10 & 0.06 \\
\hline
\end{tabular}


At the first step of EDBA implementation, the selection index rating matrix is formed using performance ratings of the team leaders along with the optimal values for each selection index as given here.

$$
[a]=\left[\begin{array}{rrrr}
0.2484 & 0.0572 & 0.1269 & 0.0246 \\
0.1458 & 0.0377 & 0.0756 & 0.0174 \\
0.054 & 0.0195 & 0.0432 & 0.0114 \\
0.0918 & 0.0156 & 0.027 & 0.0066 \\
0.2484 & 0.0572 & 0.1269 & 0.0246
\end{array}\right] \text {. }
$$

Now, the standardized and composite distance matrices are formed as per the procedure described earlier and are given below. The average and the standard deviation values are calculated and obtained as $(0.081,0.0169,0.0411,0.0084)$ and $(0.0844,0.0190,0.0440,0.0077)$ respectively.

$$
\left[Z_{s}\right]=\left[\begin{array}{rrrr}
1.342554 & 1.294786 & 1.332952 & 1.234427 \\
0.127862 & 0.272587 & 0.168534 & 0.308607 \\
-0.95897 & -0.68147 & -0.56689 & -0.46291 \\
-0.51145 & -0.88591 & -0.9346 & -1.08012 \\
1.342554 & 1.294786 & 1.332952 & 1.234427
\end{array}\right] \quad\left[Z_{d}\right]=\left[\begin{array}{rrrr}
0 & 0 & 0 & 0 \\
1.475477 & 1.044892 & 1.355869 & 0.857143 \\
5.297003 & 3.905573 & 3.60939 & 2.880952 \\
3.43733 & 4.755418 & 5.141784 & 5.357143
\end{array}\right]
$$

The composite distance matrix $\left[Z_{d}\right]$ so formed is further used to calculate the composite distance value for each of the alternative i.e. team leader from the optimal point, OPTIM. Finally, the team leaders are ranked according to this composite distance value. The team leader having the least value of composite distance will be ranked at first position and the team leader having maximum value will be ranked at last position. The rankings of team leader's along with their composite distance value obtained by implementing the proposed approach i.e. EDBA is provided in table 3.

Table 3

Rankings of Team Leaders obtained from EDBA

\begin{tabular}{cccc}
\hline S. No. & Team Leader & Composite Distance & Position/Rank \\
\hline 1 & Team Leader - A & 0 & 1 \\
2 & Team Leader - B & 2.175633 & 2 \\
3 & Team Leader - C & 3.961429 & 3 \\
4 & Team Leader - D & 4.323387 & 4 \\
\hline
\end{tabular}

In order to validate the proposed approach i.e. EDBA, the rankings of team leaders obtained from EDBA is also compared with the rankings obtained from a well known MCDM approach namely, Analytical Hierarchy Process (AHP) developed by Saaty (1980). The comparison results of the rankings of these two approaches EDBA and AHP are further provided in Table 4 that shows that there are no significant differences between the rankings obtained from these approaches.

\section{Table 4}

Comparative Rankings obtained from EDBA and AHP

\begin{tabular}{cccccc}
\hline S. No. & Team Leader & Fitness Value & Position/Rank & Fitness Value & Position/Rank \\
\hline 1 & Team Leader - A & 0 & 1 & 0.46 & 1 \\
2 & Team Leader - B & 2.175633 & 2 & 0.27 & 2 \\
3 & Team Leader - C & 3.961429 & 3 & 0.13 & 4 \\
4 & Team Leader - D & 4.323387 & 4 & 0.14 & 3 \\
\hline
\end{tabular}




\section{Discussions and Findings}

In the present study, an MCDM approach namely EDBA has been applied and demonstrated for the selection of team leader in the software development. The major findings of this research are discussed here. According to EDBA, the alternative having minimum composite distance value will be placed the first position i.e. rank -1 and the alternative having maximum value will occupy the last position i.e. rank -4 . The rankings of the team leaders obtained from EDBA provided in table 3 depicts that the team leader $-\mathrm{A}$ has occupied the first rank having the minimum composite distance value $(0)$ and the team leader $-\mathrm{D}$ has occupied the last position i.e. rank -4 having maximum composite distance value as (4.323387). The graphical representation of these rankings is also provided in Fig. 4.

A novel attempt is also made in the present study to validate the proposed approach, EDBA by comparing the results obtained from EDBA with oldest MCDM approach namely, AHP that is already implemented for the team leader selection problem. The comparative rankings provided in Table 4 depicts no significant difference between the rankings obtained from these two. The difference exists only in the ranking of team leader $-\mathrm{C}$ and $\mathrm{D}$, they occupy last and second position (rank -3 and 4 ) in accordance to EDBA whereas rank -4 and 3 using AHP respectively. Further, it is also observed that there is a very short difference as 0.01 between the fitness value of team leader $-\mathrm{C}$ and team leader $\mathrm{D}$. The reason of the ranking differences in the ranking of team leader $-\mathrm{C}$ and $\mathrm{D}$ arises due to nonconsideration of priority weights of the selection indexes in AHP. The graphical representation of the comparative rankings is also provided here in Fig. 5.

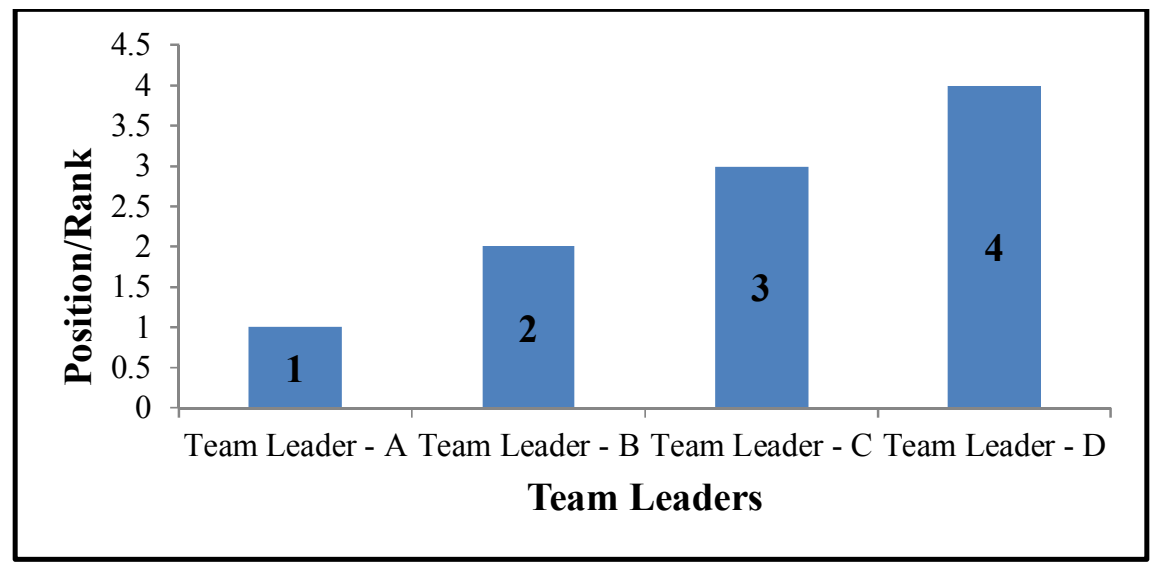

Fig 4. Rankings of Team Leaders obtained from EDBA

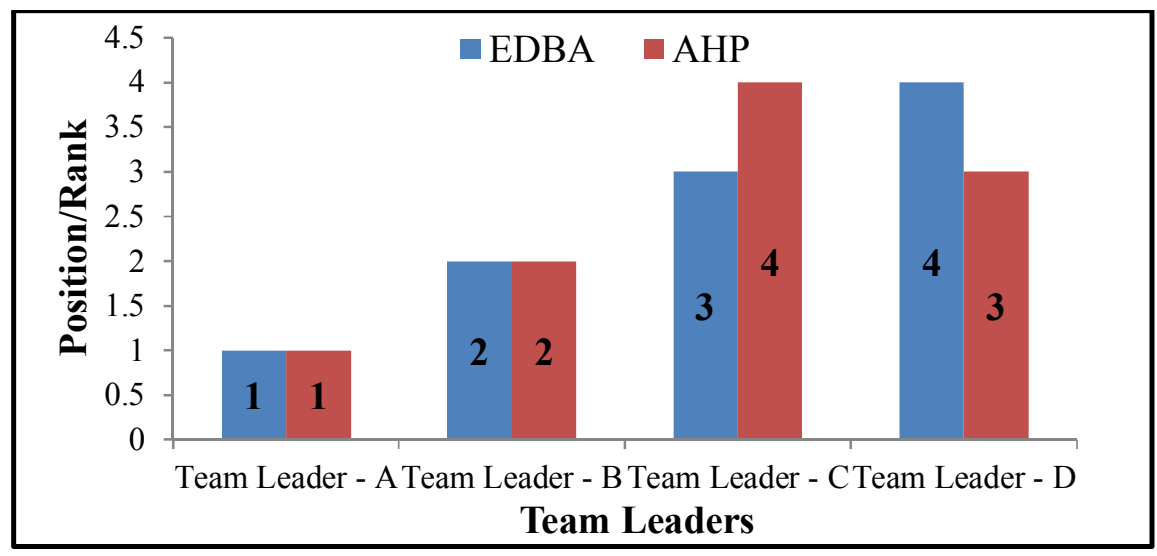

Fig 5. Comparative Rankings obtained from EDBA and AHP 


\section{Conclusions}

The present study provides the step-wise procedure for the selection of team leader in IT sector by implementing Euclidean Distance Based Approximation (EDBA) approach that is based on the simple mathematical matrix operations. The team leader selection process framework developed in this study can be used to solve the present problem i.e. team leader selection by the decision makers to made a precise selection. The proposed approach takes a lot of advantages over the existing MCDM approaches such as consideration of priority weights of selection indexes, less complexity, easy to implement etc. This work can be further extended in various aspects such as more selection indexes consideration and the development of computerized decision support system.

\section{References}

Acuña, S. T., Gómez, M., \& Juristo, N. (2009). How do personality, team processes and task characteristics relate to job satisfaction and software quality?. Information and Software Technology, 51(3), 627-639.

Alkadi, G., \& Beaubouef, T. (2008). An experimental group for researching and developing software. Journal of Computing Sciences in Colleges, 23(6), 104-109.

Amit, G., Ramesh, K., \& Tewari, P. C. (2014). Ranking of inventory policies using distance based approach method. World Academy of Science, Engineering and Technology, International Journal of Mechanical, Aerospace, Industrial, Mechatronic and Manufacturing Engineering, 8(2), 395-400.

Antoniadis, D. (2012). Complexity and the process of selecting project team members. Journal for the Advancement of Performance Information \& Value, 4(1).

Capretz, L. F., \& Ahmed, F. (2010). Making sense of software development and personality types. IT professional, 12(1).

Deniz, C., \& Metin, N. (2009). Using analytic hierarchy process for selecting the appropriate host country to study English language abroad. International Journal of Social Sciences and Humanity., 1.

Figl, K. (2010). A systematic review of developing team competencies in information systems education. Journal of Information Systems Education, 21(3), 323.

Garg, R. K., Sharma, K., Nagpal, C. K., Garg, R., Garg, R., \& Kumar, R. (2013). Ranking of software engineering metrics by fuzzy-based matrix methodology. Software Testing, Verification and Reliability, 23(2), 149-168.

Garg, R., Sharma, R., \& Sharma, K. (2016). Ranking and selection of commercial off-the-shelf using fuzzy distance based approach. Decision Science Letters, 5(2), 201-210.

Garg, R., Sharma, R., \& Sharma, K. (2017). MCDM based evaluation and ranking of commercial offthe-shelf using fuzzy based matrix method. Decision Science Letters, 6(2), 117-136.

Gilley, J. W., Morris, M. L., Waite, A. M., Coates, T., \& Veliquette, A. (2010). Integrated theoretical model for building effective teams. Advances in Developing Human Resources, 12(1), 7-28.

Gupta, A., Garg, R. K., \& Tewari, P. C. (2013). Multi-criteria ranking of inventory ordering policies using fuzzy based-distance based approach for Indian automotive industry. $i$-Manager's Journal on Management, 8(1), 41.

Gupta, V. K., \& Garg, R. K. (2004). Optimal investment planning model for power plants.

Humphrey, W. S. (2006). TSP Leading a Development Team. Pearson Education. 2006.

Jain, D., Garg, R., \& Bansal, A. (2015). A Parameterized Selection And Evaluation Of E-Learning Websites Using TOPSIS Method. International Journal of Research \& Development in, 12-26.

Jain, D., Garg, R., Bansal, A., \& Saini, K. K. (2016). Selection and ranking of E-learning websites using weighted distance-based approximation. Journal of Computers in Education, 3(2), 193-207.

Jarial, S. K., \& Garg, R. K. (2012). Ranking of vendors based on criteria by MCDM-matrix method-a case study for commercial vehicles in an industry. International Journal of Latest Research in Science and Technology, 1(4), 337-341. 
Marques, M., \& Ochoa, S. F. (2014, April). Improving teamwork in students software projects. In Software Engineering Education and Training (CSEE\&T), 2014 IEEE 27th Conference on (pp. 99-108). IEEE.

Omar, M., \& Syed-Abdullah, S. L. (2010, June). Identifying effective software engineering (SE) team personality types composition using rough set approach. In Information Technology (ITSim), 2010 International Symposium in (Vol. 3, pp. 1499-1503). IEEE.

Omar, M., Syed-Abdullah, S. L., \& Hussin, N. M. (2011, November). Developing a team performance prediction model: A rough sets approach. In International Conference on Informatics Engineering and Information Science (pp. 691-705). Springer Berlin Heidelberg.

Mazni, O., Syed-Abdullah, S. L., \& Hussin, N. M. (2010, December). Analyzing personality types to predict team performance. In Science and Social Research (CSSR), 2010 International Conference on (pp. 624-628). IEEE.

Palmer, G., \& Summers, J. (2011). Characterization of leadership within undergraduate engineering design teams through case study analysis. Proceedings of the 18th International Conference on Engineering Design (ICED 11), Impacting Society through Engineering Design.

Rong, G., \& Shao, D. (2012, April). Delivering software process-specific project courses in tertiary education environment: Challenges and solution. In Software Engineering Education and Training (CSEE\&T), 2012 IEEE 25th Conference on (pp. 52-61). IEEE.

Rovira, N., Özgen, S., Medir, M., Tous, J., \& Alabart, J. R. (2012). Human values in the team leader selection process. The Spanish journal of psychology, 15(01), 216-226.

Rutherfoord, R. H. (2006, October). Using personality inventories to form teams for class projects: a case study. In Proceedings of the 7th conference on Information technology education (pp. 9-14). ACM.

Saaty, T.L. (1980). The analytic hierarchy process. New York: McGraw-Hill, 1980.

Tseng, H., Wang, C., Ku, H., \& Sun, L. (2010). Key factors in online collaboration and their relationship to team works satisfaction. Quarterly Review of Distance Education, 10, 195-206.

Yu, H., Bao, X., \& Yang, S. (2009, March). Research and improvement of team software process. In Computer Science and Information Engineering, 2009 WRI World Congress on (Vol. 7, pp. 654658). IEEE.

Zaccaro, S. J., Rittman, A. L., \& Marks, M. A. (2002). Team leadership. Leadership, 12(4), 451-483.

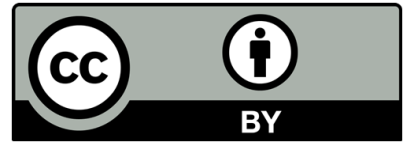

(C) 2017 by the authors; licensee Growing Science, Canada. This is an open access article distributed under the terms and conditions of the Creative Commons Attribution (CC-BY) license (http://creativecommons.org/licenses/by/4.0/). 